\title{
Comparison of Stator-Permanent-Magnet Brushless Machines
}

\author{
Chunhua Liu ${ }^{1}$, K. T. Chau ${ }^{1}$, J. Z. Jiang ${ }^{1,2}$, and Shuangxia Niu ${ }^{1}$ \\ ${ }^{1}$ Department of Electrical and Electronic Engineering, The University of Hong Kong, Hong Kong, China \\ ${ }^{2}$ Department of Automation, Shanghai University, Shanghai 200072, China
}

\begin{abstract}
This paper quantitatively compares two emerging stator-permanent-magnet (PM) machines, namely, the doubly salient PM and the PM hybrid brushless types. Both of them are attractive for electric vehicles and wind power generation. For comparison, both machines adopt the outer-rotor 36/24-pole topology and are designed based on the same peripheral dimensions. By using the circuit-field-torque time-stepping finite element analysis (CFT-TS-FEM), both steady-state and transient performances of the two machines are critically compared.
\end{abstract}

Index Terms-Finite element method, machine analysis, machine design, permanent-magnet (PM) machine.

\section{INTRODUCTION}

D UE to inherently high efficiency and high power density, permanent-magnet (PM) brushless machines have been widely used for various applications. The corresponding stator-PM versions, including the doubly salient PM (DSPM) and PM hybrid brushless (PMHB), take the definite advantage of high mechanical integrity [1]. Their outer-rotor topologies are particularly attractive, because they enable direct driving for electric vehicles (EVs) [2] and wind power generation [3], [4]. However, a quantitative comparison of these two emerging machines is absent in literature.

The purpose of this paper is to quantitatively compare the DSPM and PMHB machines based on the same peripheral dimensions. For comparison, both machines will adopt the outer-rotor 36/24-pole topology. The key is to employ the circuit-field-torque time-stepping finite element method (CFT-TS-FEM) [5] to analyze the steady-state and transient characteristics of both machines.

\section{Machine Structures And Features}

Figs. 1(a) and 2(a) show the structures of the two stator-PM machines. Both the DSPM and PMHB machines adopt the outer-rotor topology. Their rotors are solid iron with 24 salient poles. Their stators have 36 salient poles wound with three-phase fractional-slot armature windings, and six PM poles. These structures have some distinct advantages. First, the rotor has neither PMs nor windings, hence offering high robustness to withstand high-speed or intermittent operation. The outer-rotor nature can enable direct coupling with tires for direct-drive EVs, or with wind blades for wind power generation. Second, the stator space can be fully utilized in such a way that the outer layer (outer stator) is for armature windings, while the inner layer (inner stator) is to accommodate the PMs and field windings. Hence, the power density can be improved. Third, the fractional-slot armature windings can shorten the magnetic flux path and the span of end-windings, which lead to reduce both iron and copper materials. Thus, it can further improve the power density. Also, this arrangement of slots can significantly reduce the cogging torque, which usually occurs at conventional PM brushless machines.

Digital Object Identifier 10.1109/TMAG.2008.2002632

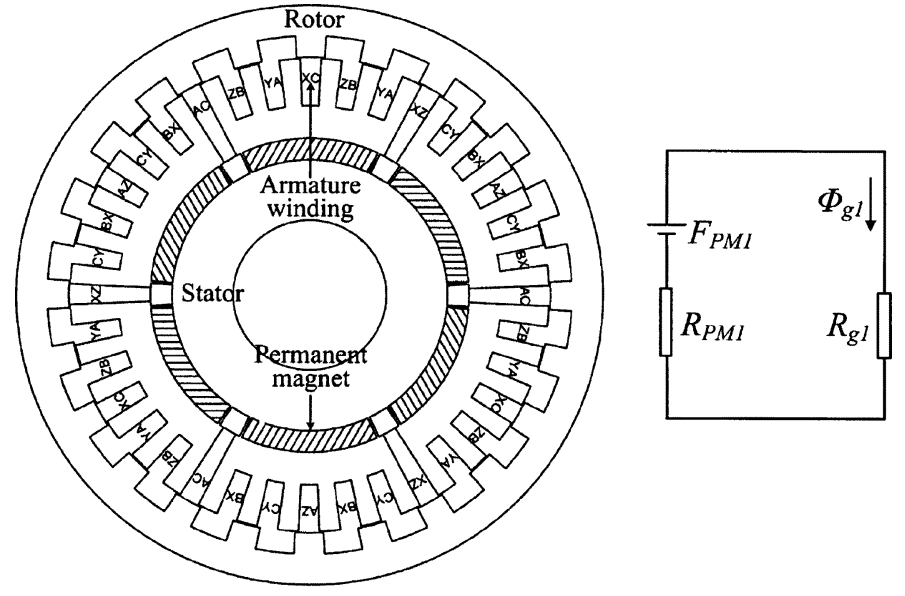

(a)

(b)

Fig. 1. DSPM machine. (a) Structure. (b) Equivalent magnetic circuit.

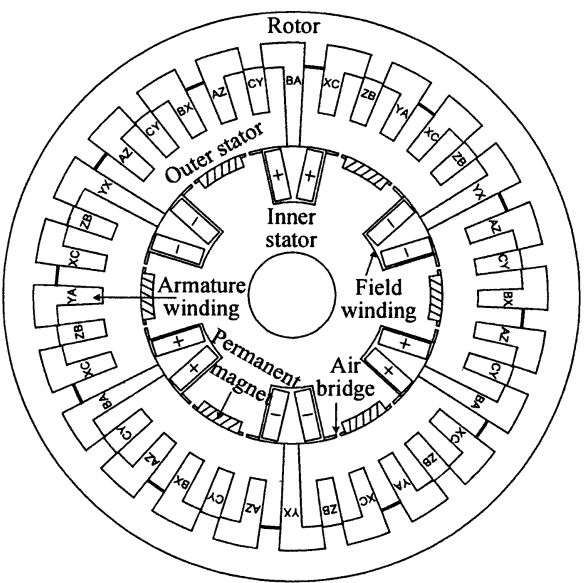

(a)

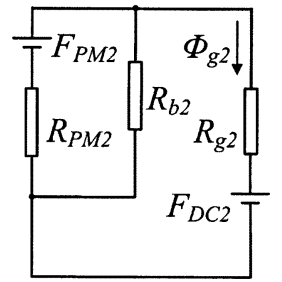

(b)
Fig. 2. PMHB machine. (a) Structure. (b) Equivalent magnetic circuit.

The key difference between the DSPM and PMHB machines is the field excitation. The DSPM machine has the PM excitation only, whereas the PMHB machine utilizes hybrid excitations [both PMs and direct current (DC) field windings]. Thus, the DSPM machine is flux uncontrollable. In contrast, the PMHB machine can provide flexible air-gap flux control, including flux strengthening and flux weakening. Also, it utilizes an additional 


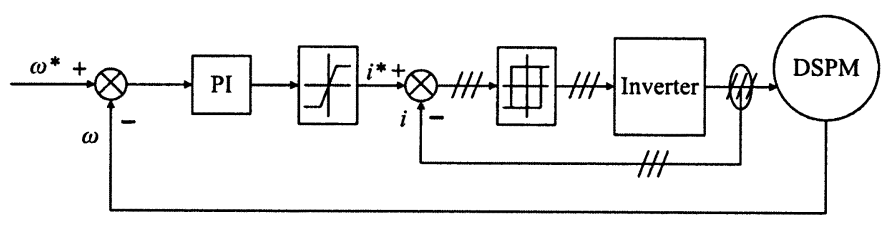

(a)

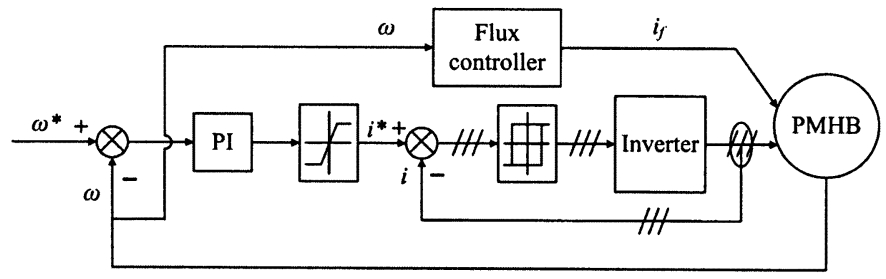

(b)

Fig. 3. Control block diagrams. (a) DSPM. (B) PMHB.

TABLE I

KEY DATA OF DSPM AND PMHB MACHINES

\begin{tabular}{lcc}
\hline \hline \multicolumn{1}{c}{ Items } & DSPM machine & PMHB machine \\
\hline Number of phases & 3 & 3 \\
Armature current density & $5 \mathrm{~A} / \mathrm{mm}^{2}$ & $5 \mathrm{~A} / \mathrm{mm}^{2}$ \\
Rotor outside diameter & $270.0 \mathrm{~mm}$ & $270.0 \mathrm{~mm}$ \\
Rotor inside diameter & $221.2 \mathrm{~mm}$ & $221.2 \mathrm{~mm}$ \\
Stator outside diameter & $220.0 \mathrm{~mm}$ & $220.0 \mathrm{~mm}$ \\
Air-gap length & $0.6 \mathrm{~mm}$ & $0.6 \mathrm{~mm}$ \\
Stack length & $80.0 \mathrm{~mm}$ & $80.0 \mathrm{~mm}$ \\
PM material & $38 \mathrm{SH} \mathrm{N}-\mathrm{Fe}-\mathrm{B}$ & $38 \mathrm{SH} \mathrm{Nd-Fe-B}$ \\
Rated power & $3.2 \mathrm{~kW}$ & $2 \mathrm{~kW}$ \\
Shaft diameter & $70 \mathrm{~mm}$ & $40 \mathrm{~mm}$ \\
Rated torque & $34 \mathrm{Nm}$ & $20 \mathrm{Nm}$ \\
Rated voltage & $380 \mathrm{~V}$ & $220 \mathrm{~V}$ \\
Speed & $900 \mathrm{rpm}$ & $0-4000 \mathrm{rpm}$ \\
Power density & $122 \mathrm{~W} / \mathrm{kg}$ & $73 \mathrm{~W} / \mathrm{kg}$ \\
PM volume & $284.8 \mathrm{~cm}$ & $54.7 \mathrm{~cm}^{3}$ \\
DC winding volume & - & $230.2 \mathrm{~cm}^{3}$ \\
\hline \hline
\end{tabular}

air bridge in shunt with each PM to amplify the flux weakening ability. The corresponding field excitation inevitably causes additional power loss. Nevertheless, this reduction of efficiency can be partially compensated by the efficiency improvement due to air-gap flux control. By properly tuning the air-gap flux density, the efficiency can be online optimized at different speeds and loads.

For the DSPM machine, the pole selection is governed by $N_{s}=2 m k$ and $N_{r}=N_{s}-2 k$, where $N_{s}$ is the number of stator poles, $N_{r}$ is the number of the rotor poles, $m$ is the number of phases, and $k$ is the integer. On the other hand, for the PMHB machine, the relationships are given by $N_{s}=4 \mathrm{mp}$ and $N_{r}=$ $2 N_{s} / m$, where $p$ is the number of pole pairs of the DC field windings. Therefore, $m=3, p=3$, and $k=6$ are selected for the two machines.

The equivalent magnetic circuits of the DSPM and PMHB machines are shown in Figs. 1(b) and 2(b), respectively, where $F_{\mathrm{PM} 1}$ and $F_{\mathrm{PM} 2}$ are their PM magnetomotive forces (MMFs), $R_{\mathrm{PM} 1}$ and $R_{\mathrm{PM} 2}$ are their PM reluctances, $R_{g 1}$ and $R_{g 2}$ are their air-gap reluctances, $R_{b 2}$ is the air-bridge reluctance of the PMHB one, and $F_{\mathrm{DC} 2}$ is the DC field winding MMF of the PMHB one. Based on the equivalent circuits, their air-gap fluxes $\Phi_{g 1}$ and $\Phi_{g 2}$ can be obtained as

$$
\Phi_{g 1}=\frac{F_{\mathrm{PM} 1}}{R_{g 1}+R_{\mathrm{PM} 1}}
$$

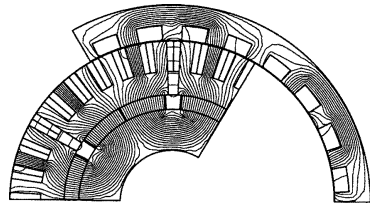

(a)

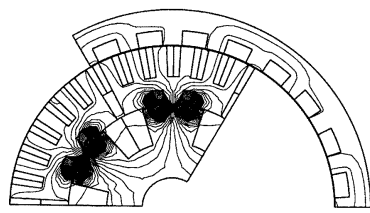

(c)

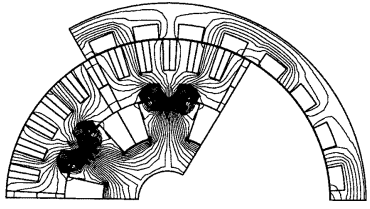

(b)

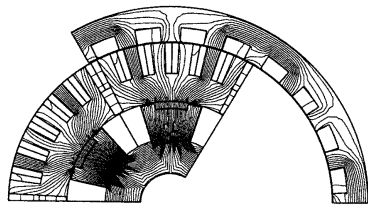

(d)
Fig. 4. Magnetic field distributions. (a) DSPM. (b) PMHB at 0 A turns. (c) PMHB at $-350 \mathrm{~A}$ turn. (d) PMHB at $+1000 \mathrm{~A}$ turns.

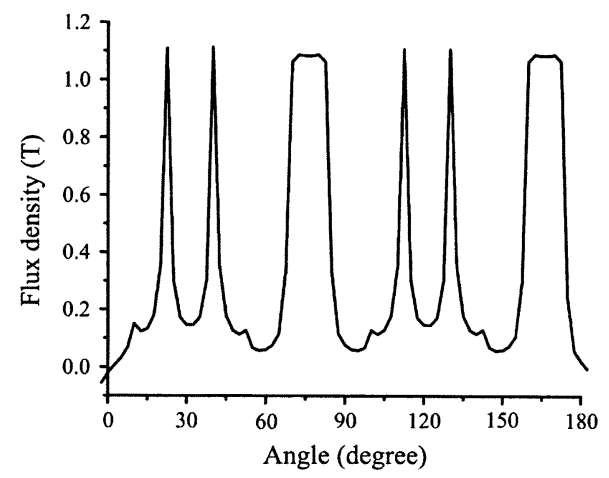

(a)

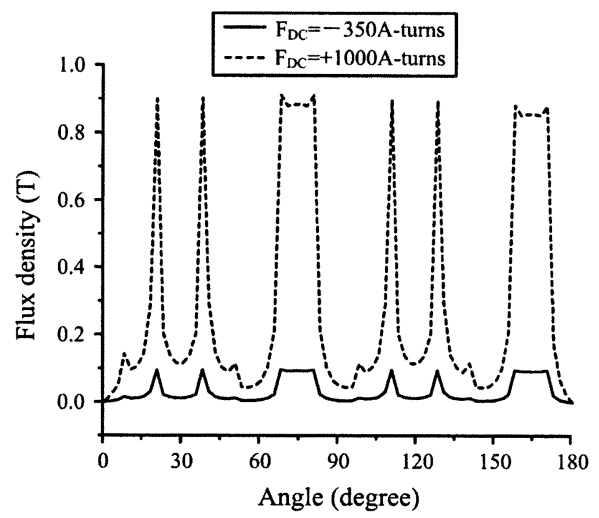

(b)

Fig. 5. Air-gap flux density distributions. (a) DSPM. (b) PMHB.

$$
\Phi_{g 2}=\frac{F_{\mathrm{DC} 2}\left(R_{b 2}+R_{\mathrm{PM} 2}\right)+F_{\mathrm{PM} 2} R_{b 2}}{R_{b 2} R_{g 2}+R_{\mathrm{PM} 2} R_{g 2}+R_{b 2} R_{\mathrm{PM} 2}} .
$$

From (1) and (2), it is obvious that the PMHB machine possesses the ability to change $\Phi_{g 2}$ by regulating $F_{\mathrm{DC} 2}$. The corresponding control strategies are shown in Fig. 3, indicating that the PMHB machine has an additional flux controller to regulate $F_{\mathrm{DC} 2}$.

\section{ANALYSIS APPROACH}

The CFT-TS-FEM consists of three sets of equations, namely, the electromagnetic field equation, the circuit equation, and the 


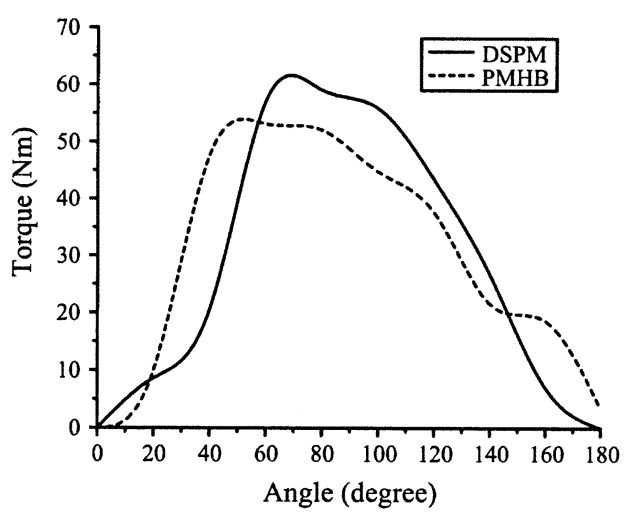

Fig. 6. Torque-angle characteristics.

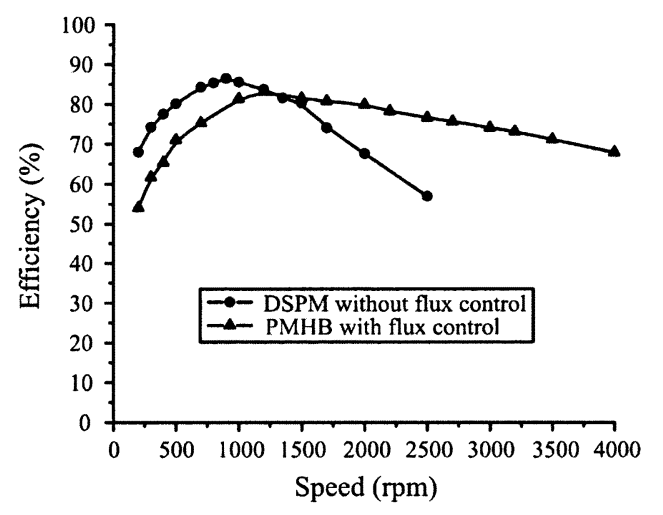

Fig. 7. Efficiency-speed characteristics.

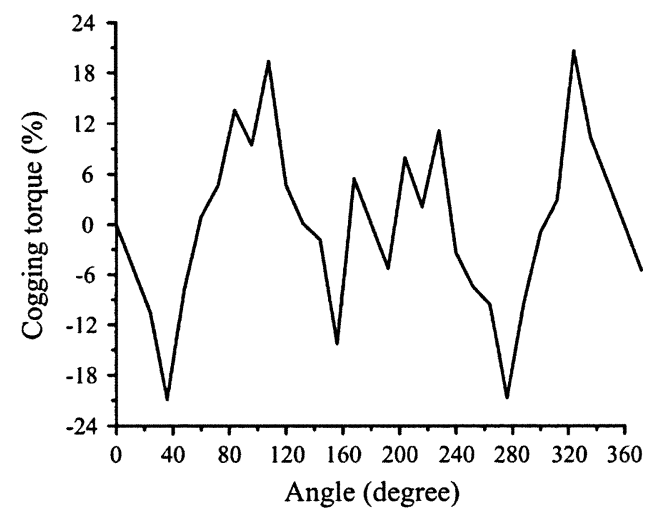

Fig. 8. Cogging torque waveform of DSPM machine.

motion equation. The field equation of both machines is governed by

$$
\begin{aligned}
\Omega: \frac{\partial}{\partial x}\left(v \frac{\partial A}{\partial x}\right)+ & \frac{\partial}{\partial y}\left(v \frac{\partial A}{\partial y}\right) \\
& =-J-v\left(\frac{\partial B_{r y}}{\partial x}-\frac{\partial B_{r x}}{\partial y}\right)+\sigma \frac{\partial A}{\partial t}
\end{aligned}
$$

where $\Omega$ is the domain of calculation, $A$ is the magnetic vector potential component along the $z$-axis, $J$ is the current density, $v$ is the reluctivity, $\sigma$ is the electrical conductivity, and $B_{r x}$ and $B_{r y}$ are the PM remnant flux density components along the $x$-axis and $y$-axis, respectively.

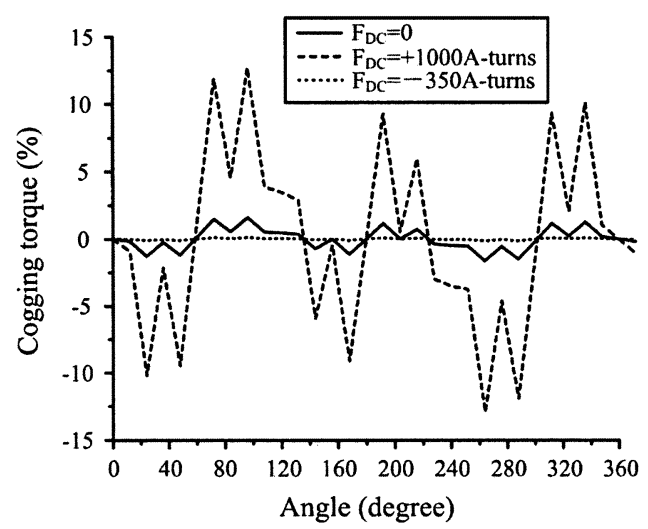

Fig. 9. Cogging torque waveforms of PMHB machine.

The circuit equation of both machines at motoring is governed by

$$
u=R i+L_{e} \frac{d i}{d t}+e \quad \text { and } \quad e=\frac{l}{S} \iint_{\Omega_{e}} \frac{\partial A}{\partial t} d \Omega
$$

where $u$ is the applied voltage, $R$ is the resistance of phase winding, $i$ is the phase current, $L_{e}$ is the inductance of the end winding, $e$ is the phase electromotive force (EMF), $l$ is the axial length of iron core, $S$ is the conductor area of each turn of phase winding, and $\Omega_{e}$ is the total cross-sectional area of conductors of each phase winding. When the machines serve for generation, the circuit equation is given by

$$
e=\left(R+R^{\prime}\right) i+\left(L_{e}+L^{\prime}\right) \frac{d i}{d t}
$$

where $R^{\prime}$ is the load resistance and $L^{\prime}$ ithe load inductance.

The motion equation of the two machines is given by

$$
J_{m} \frac{d \omega}{d t}=T_{e}-T_{L}-\lambda \omega
$$

where $J_{m}$ is the moment of inertia, $\omega$ is the rotor speed, $T_{e}$ is the electromagnetic torque, $T_{L}$ is the load torque, and $\lambda$ is the damping coefficient.

After discretization, the above equations are solved at each time step. Consequently, both steady-state and transient performances of both machines can be calculated.

\section{Comparison of Machine Performances}

Based on the same peripheral dimensions, the two machines are designed. Their key design data are listed in Table I. Because the DSPM machine can accommodate more PMs than the PMHB one, its power density is higher by $67 \%$. However, this merit in power density is offset by the high cost of PMs. Based on the present international rates, the PM material cost of the PMHB machine is only $\$ 22.3$, which is much lower than the $\$ 116.3$ of the DSPM one. It should be noted that additional cost needs to be paid for the field control of the PMHB machine.

By using the CFT-TS-FEM, the magnetic field distributions of the two machines at no-load are depicted in Fig. 4. It can be seen that the DSPM machine has a fixed field pattern, whereas the PMHB machine exhibits different field patterns at different field winding excitations ( 0 A turns, -350 A turns, and $+1000 \mathrm{~A}$ turns). Then, the air-gap flux density distributions of the PMHB machine are shown in Fig. 5. It illustrates that the 


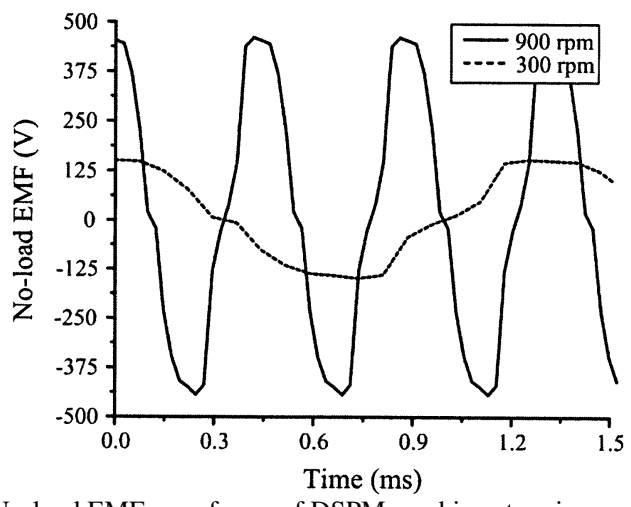

Fig. 10. No-load EMF waveforms of DSPM machine at various speeds.

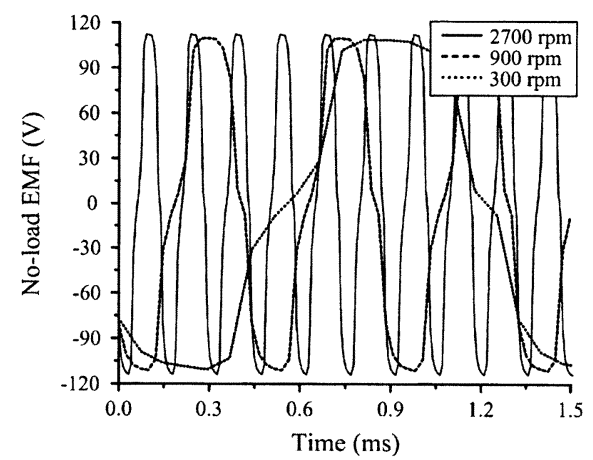

Fig. 11. No-load EMF waveforms of PMHB machine at various speeds.

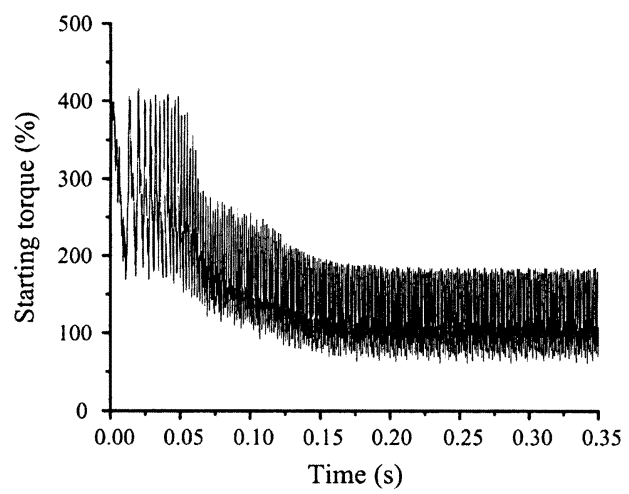

Fig. 12. Transient torque response at startup of DSPM machine.

PMHB machine can offer a very wide range of flux regulation (up to nine times).

Due to the use of more PMs, the DSPM machine can definitely produce higher torque than the PMHB machine. Nevertheless, as shown in Fig. 6, the PMHB machine can utilize flux strengthening to achieve the torque up to $85.7 \%$ of the DSPM one, even though its PM volume is only $19.2 \%$ of the DSPM one. Also, taking into account the field winding losses, the efficiency-speed characteristics of the two machines are compared as shown in Fig. 7. Although the PMHB machine offers lower efficiency (below $1300 \mathrm{r} / \mathrm{min}$ ) than the DSPM one, the PMHB machine can significantly extend the operating range up to $4000 \mathrm{r} / \mathrm{min}$ and can provide flux weakening to achieve higher efficiency at high speeds (1300-4000 r/min) than the DSPM one. Moreover, because the PMHB machine inherently provides lower air-gap flux density than the DSPM one while it has a similar tooth-slot structure, the PMHB machine can offer significantly lower cogging torque than the DSPM one as depicted in Figs. 8 and 9.

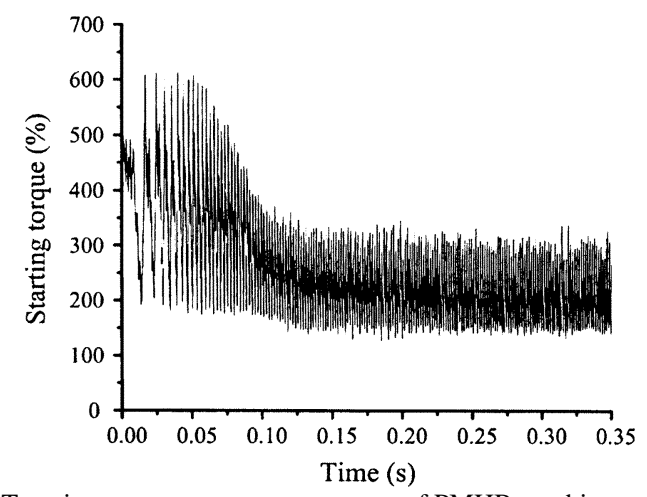

Fig. 13. Transient torque response at startup of PMHB machine.

Figs. 10 and 11 show the no-load EMF waveforms of the two machines at different speeds. Because of uncontrollable flux, the DSPM machine generates speed-dependent EMF waveforms. On the contrary, the PMHB machine can uniquely achieve constant-amplitude EMF waveforms by the use of flux strengthening at $300 \mathrm{r} / \mathrm{min}$ and flux weakening at $2700 \mathrm{r} / \mathrm{min}$. This property is particularly useful for wind power generation. On the other hand, Figs. 12 and 13 show the transient starting torque responses (normalized by the rated values) of the two machines under a load torque of $40 \mathrm{Nm}$. Their armature currents are limited to two times the rated value. It can be seen that the PMHB machine can produce much higher starting torque in the presence of flux strengthening at $750 \mathrm{~A}$ turn. This property is particularly useful for cranking the engine of hybrid EVs.

\section{CONCLUSION}

Two emerging stator-PM machines (the DSPM and PMHB types) have been quantitatively compared. Based on the same peripheral dimensions and outer-rotor 36/24-pole topology, the two machines have undergone detailed performance analysis. Compared with the DSPM machine, the PMHB machine takes the definite merit of flux controllability, hence achieving better efficiency profile, lower cogging torque, higher starting torque, and constant voltage generation over a wide speed range.

\section{ACKNOWLEDGMENT}

This work was supported by Research Grants Council, Hong Kong Special Administrative Region, China, under Grant HKU7105/07E.

\section{REFERENCES}

[1] Z. Q. Zhu and D. Howe, "Electrical machines and drives for electric, hybrid, and fuel cell vehicles," IEEE Proc., vol. 95, no. 4, pp. 746-765, Apr. 2007.

[2] K. T. Chau and C. C. Chan, "Emerging energy-efficient technologies for hybrid electric vehicles," IEEE Proc., vol. 45, no. 4, pp. 821-835, Apr. 2007.

[3] K. T. Chau, Y. B. Li, J. Z. Jiang, and S. Niu, "Design and control of a PM brushless hybrid generator for wind power application," IEEE Trans. Magn., vol. 42, no. 10, pp. 3497-3499, Oct. 2006.

[4] C. Liu, K. T. Chau, J. Z. Jiang, and L. Jian, "Design of a new outer-rotor permanent magnet hybrid machine for wind power generation," IEEE Trans. Magn., vol. 44, no. 6, pp. 1494-1497, Jun. 2008.

[5] Y. Wang, K. T. Chau, C. C. Chan, and J. Z. Jiang, "Transient analysis of a new outer-rotor permanent-magnet brushless dc drive using circuitfield-torque time-stepping finite element method," IEEE Trans. Magn., vol. 38, no. 2, pp. 1297-1300, 2002.

Manuscript received March 01, 2008. Current version published December 17, 2008. Corresponding author: C. Liu (e-mail: chualiu@eee.hku.hk). 